This item was submitted to Loughborough's Research Repository by the author.

Items in Figshare are protected by copyright, with all rights reserved, unless otherwise indicated.

\title{
Examining student-designed games through Suits' theory of games
}

PLEASE CITE THE PUBLISHED VERSION

http://dx.doi.org/10.1080/13573322.2014.994174

PUBLISHER

(c) Taylor \& Francis

VERSION

AM (Accepted Manuscript)

PUBLISHER STATEMENT

This work is made available according to the conditions of the Creative Commons Attribution-NonCommercialNoDerivatives 4.0 International (CC BY-NC-ND 4.0) licence. Full details of this licence are available at: https://creativecommons.org/licenses/by-nc-nd/4.0/

\section{LICENCE}

CC BY-NC-ND 4.0

\section{REPOSITORY RECORD}

Casey, Ashley, Peter Hastie, and Steve Jump. 2019. “Examining Student-designed Games Through Suits' Theory of Games". figshare. https://hdl.handle.net/2134/22722. 


\section{Examining Student Designed Games through Suits’ Theory of Games}

2

\section{Corresponding Author}

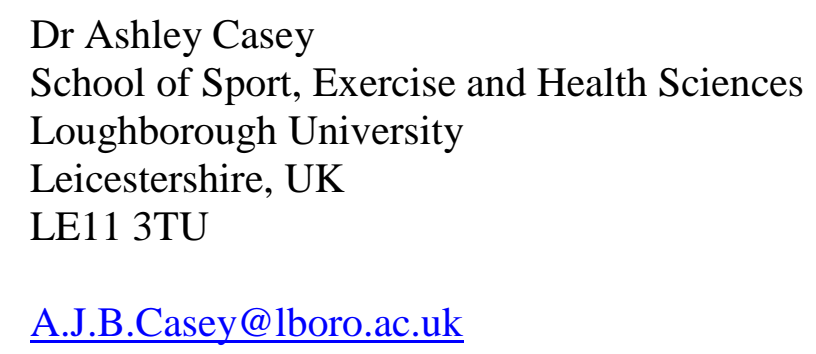

$$
\text { Ashley Casey }^{12} \text {, Peter Hastie }{ }^{3} \text { and Steve Jump }{ }^{4}
$$

${ }^{4}$ Physical Education Department, Beaumont School 


\section{Examining Student Designed Games through Suits’ Theory of Games}

\section{Abstract}

This paper documents how a unit of student-designed games can create a more meaningful version of Physical Education for disengaged students; a version that enhances the educational legitimacy of the subject matter by affording it worth in and of itself rather than being justified for other, extrinsic or instrumental reasons. Furthermore, it seeks to develop new knowledge relating to the conduct of game instruction within physical education, by using Suits' theory of games. Drawing on Suits' theory we develop a conceptual model that is intended to represent the hierarchical processes that occur in game play through studentdesigned games. This model is then tested via examination of the experiences of a cohort of teachers and their year 10 students from a mixed secondary school in the greater London area. From our discussions with the students, it is argued that the key focus of the games that these students were used to playing was the need to "play the game well". By contrast, we suggest that it is possible to provide more meaningful experiences to students if a more philosophically-driven and less efficiency-driven approach to games is taken, following Suits’ (1978) lead more closely. By exploring the loop between and around lusory means, lusory goals and constitutive rules (the aspects of Suits' (1978) theory that have been shown to represent student-designed games) students engage with a more meaningful games experience than simply playing the game well. This 'new' approach to games may offer counter balance to the ideological tendencies now emphasised in countries and contexts that celebrate instrumental outcomes of performative Physical Education and Sport rather than affording worth in and of itself to the curriculum's subject matter.

Keywords: Games making, game theory, physical education, Bernard Suits, game appreciation 


\section{Examining Student Designed Games through Suits Theory of Games}

A number of educational philosophers have taken a stance that is best represented by Tinning (2009, p. 151) when he suggested that the educational legitimacy of a curriculum's subject matter is contingent on its activities having worth in and of themselves rather than being justified for other, extrinsic or instrumental reasons. Tinning (2009), like Arnold (1985) and Peters (1996) before him, argued that physical education was increasingly seen in instrumental terms. Using the UK as an example he suggested that the then Labour government - although we would argue successive governments - believed that physical education, through its increasingly popular moniker of school sport, could be important in delivering on instrumental outcomes such as ‘sports talent ID’, ‘decreasing obesity’, and ‘citizenship’. However, while it might be argued that these are laudable goals they are also dangerous goals (Tinning, 2009), as their outcomes are not only achieved in a multifarious and unpredictable future, but it may also very difficult to prove that physical education played any role in their achievement. By tying ourselves to these ethereal outcomes we run the risk of becoming badly unstuck; especially when considering how poorly disconnected physical education seems to be from a curriculum capable of achieving these goals (Ennis, 2000).

Writing in the same monograph Kirk (2009) and Siedentop (2009), among others, argued that, as a field, physical education needed to help children (and the adults they become) to value the physically active life. Both did this by asking us to consider how children gain 'capital' ["changes in persons that form skill and capabilities that enable them to act in new ways” Siedentop (2009, p. 13)] through physical education. In contrast to this aspiration many have argued that physical education has repeatedly asked persons to act in old and established ways and has almost singularly failed to achieve its stated aims. Indeed 
such is the volume of work making this claim that it seems futile to guide the reader to a single work or author. Suffice to say that, as a field, our hopes, beliefs and aspirations do not match our curriculum or pedagogies. Capital is currently gained not through enabling curricula but through measures of performativity (Evans, 2013). Physical education and its subject matter have been molecularized to help teachers break content down into its smallest unit, ergo its most teachable form (Jones, Harvey, \& Kirk, 2014) and these molecules (e.g. the handstand or the penalty shot) have become the measures against which performativity is gauged.

It has been argued that "sport is our subject matter" (Siedentop, 1982) and that "to those looking in from the outside, the playing of games and sport within physical education would seem the raison d'être of the subject (Casey \& Hastie, 2011, p.296) and yet the same molecularized notion of sport is not taken in wider society. Indeed, such is the prevalence of games in wider society that they occupy an almost unrivalled place in everyday life; a place that seems to go unquestioned. In contrast the manner in which they are transferred into education, through school sport, has long been questioned (Siedentop, 1982). Consequently the capital that is 'won' and 'lost' outside of school - in Sunday leagues and recreational settings - is only bestowed in physical education on those whose contributions meet the measures of performativity that we apply in physical education and school sport. In the next section we will explore the gulf that appears to exist between the "rich [and] impoverished meaning” we afford games in and out of schools respectively.

\section{Games as society}

Games - in every form imaginable - occupy a plethora of positions in society generally and in our lives specifically. They are ubiquitous and yet are translated and transformed in so many different ways by different people and different cultures. Games can take on the form of jocular play or serious competition, can occur in organised activities 
(such as international sport, club sport, and school curricular [the focus of this paper] and extra-curricular provision) or in the form of ad hoc games between friends, and can be scaled from solo to mass participation games. In his exploration of the practical philosophy of sport, Kretchmar (1994) asked us to consider three questions with regards to games and, by default, play: (i) why do games exist in every culture?; (ii) how does something that is "only a game" become responsible for a trillion dollar global industry; and indeed (iii) is too much play harmful?

All of these questions, Kretchmar suggests, appear to go against the idea that play (and by association games) is an inherently bad thing and yet, it appears, play is readily positioned as something that we are expected to leave behind us as we get older. This sentiment is exemplified in the notion that children need to "grow up" and take things "more seriously" and in the idea that "making a game out of something” is a bad thing to do. In contrast, Morgan (2006) argues that sport, games and physical education are among the most important and serious of all human activities. To play games, Morgan argues, should be the reasons that we work rather than being positioned as thing we might do when we are not working. In changing the position and increasing the value we place on sport, games and physical education, we reposition them as meaningful and highly valued experiences rather than simply seeing them as a form of escapism.

Developing this argument further, Kretchmar (2001) suggests that for an activity to be considered as a central part of an active lifestyle it needs to be meaningful. Meaning, he believes, is currently positioned as a "vague, homogenous thing" (p. 260) rather than being considered across the full spectrum of importance (i.e. unimportant to vitally important). Consequently we lack the wherewithal to acknowledge impoverished forms of meaning (where we acknowledge, yes, perhaps, that might be important at some stage in our lives) and rich forms of meaning (in its heights and depths, and in its here and now importance) 
that motivate us to get involved, be involved and stay involved in something. This simple fact, Kretchmar (2001) argues, is that "meaning varies as widely as the levels of fitness and skills we see in our students" (p. 260). Furthermore "when we fail to distinguish rich from impoverished meaning, we miss a marvellous opportunity to strengthen our pedagogy and win more converts to the active lifestyle” (Kretchmar, 2001, p. 261). The question is, therefore, does physical education present itself as meaningful?

Fundamentally, however, making something meaningful is not as simple as providing opportunities to play. If it were then rolling out the ball would be a far more successful approach to physical education than it is at present. Play, in Kretchmar’s (2007) opinion, “is typically overrated...games, in fact, tell us more about our distinctive humanity than does play” (p.1). He notes:

First, play is more primitive than games. It comes first in terms of evolution and childhood development, and it is accessible to lesser animals. Second, games require more impressive intellectual operations than play. A sentient being, in other words, has to be much smarter to negotiate games than play, and this can be shown by the cognitive operations required for each activity. Third, games are artifacts, conventions, and thus first cousins of art, literature, and other forms of culture. Play, on the other hand, exists and thrives with or without culture.

(Kretchmar, 2007, p.1)

At the heart of Kretchmar's line of reasoning is the argument that games are uniquely human and give meaning to being human. However, many noted sport pedagogy scholars have voiced particular dissent with respect to current practices of games instruction within physical education. For example, in his description of "physical education as sporttechniques”, Kirk (2010) suggests that pride of place in current physical education is given to the techniques of games and sports over the performance of the games and sports themselves, resulting in the practice of discrete specific movements out of the game situation. Indeed, criticism of this practice was born out in the genesis of the pedagogical model called "Sport 
Education”, where Daryl Siedentop (1994) used the terms inauthentic and decontextualized to describe how sport was presented to students in school physical education.

In positioning physical education as "sport-techniques", this paper argues that we are missing a vital step; one that is, perhaps, overlooked far too often when we seek to defend the current incarnation of physical education in our schools. That is, for children (and the adults they become), the physical education they receive in the present will have a strong influence upon their decisions with respect to future engagement in physical education and physical activity. Currently that decision revolves around two ideas. First, since games (and by default physical education because of the way it positions teams games as its raison d'etre) are not seen seriously, they are overlooked in favour of more important pursuits such as passing exams and getting a good job. Second, because games are reduced to techniques they are no longer even seen as play and are therefore afforded impoverished meaning in our lives rather than being distinguished by their richness of value and meaning.

Aside from the focus on sports techniques, Ennis (2000) critiques games instruction in which students participate in units where there are minimal instructional periods and few policies to equalities playing opportunities for low skilled players. Ennis argues that this sets up cases in physical education where students must rely essentially on previous experiences with sport which reproduces an "elitist perspective on sport" (Ennis, 2000, p. 121). As a result, these lower skilled students (together with or those who do not fit within the high status definintions constructed by the dominant class members) find little interest or meaning in physical education and lack the willingness to expend effort or participate in physical education activities. In fact, Rovengo (2008) suggests that one of the top challenges facing physical education is to address inequitable opportunities to learn and participate in physical activities and hence improve the quality experiences for those children and adolescents who feel alienated and disengaged. 
One response to student alienation in games instruction has been the advent of student-designed games. Described as the process in which students create and practice their own games, and in which the teacher as facilitator is able to guide and establish certain limits (Hastie, 2010), recent research has suggested that that student-designed games units have the capacity to free young people to define competition at their own developmental level (Casey \& Hastie, 2011), and that all students are able to develop some basic understanding of how game rules both enable and constrain certain tactics and skills (Hastie, \& André, 2012). Further, when the focus was placed upon student learning, Casey, Hastie, and Rovegno (2011) noted that student-designed games provides a forum that allows students to develop a more sophisticated understanding of game structures and game play. In other words, and revisiting (and reworking) Kretchmar’s (2007) ideas, student-designed games are positioned as more impressive intellectual operations than learning techniques, allowing children the chance to negotiate games and their rules rather than performing already learned techniques, and help learners to define games as artefacts or conventions.

Drawing on the work of Bernard Suits, a games-theorist and philosopher, the purpose of this paper was to provide answers to the following three key questions. These were: (1) How does a unit of student-designed games add to the meaning that previously disengaged students see in physical education? (2) To what extent can Suits' theory of games be modified to explain these student responses? (3) To what extent can Suits' theory help provide a deeper explanation of the previous findings of student-designed games that students appreciate engagement? The answers to these questions may help to create new knowledge relating to the conduct of game instruction within physical education. In particular, they may help to determine if student-designed games might be positioned as rich and meaningful experiences for young people.

\section{Suits' theory of games, life and utopia}


Much of the analysis considered in this paper is shaped by Bernard Suits' (1978) work The Grasshopper, along with the work of Scott Kretchmar who drew on Suits' ideas. Both argue that work and working is about doing things as efficiently as possible. In contrast games are the complete opposite. Take golf as an example. Carrying the ball to the hole would be an instrumentally better way of achieving the best score, but to do so takes away the intrinsic value of the sport, or that crossing the finishing line in a running race more easily achieved by simply crossing the infield rather than running around the track. Yet this is not the reason that we play games. Put most simply "playing a game is the voluntary attempt to overcome unnecessary obstacles” (Suits, 1978, p. 41).

In his treatise on games, Suits argues that four hierarchical processes occur when we engage in game play. Firstly we agree to try and achieve a prelusory goal. Taken from the Latin ludus meaning game, Suits (1978) suggested that prelusory should be considered to be the pre-game goal. In the case of golf this would "involve getting an object (a ball) to a series of targets (the holes) in as few tries as possible” (Kretchmar, 2007, p. 7). Secondly the player agrees to do this by lusory means, only the permitted rules. Often this means abiding by the constitutive rules, a set of rules that prohibit the use of more efficient rules in favour of the quirky rules of the game (i.e. using a series of different metal clubs to hit the ball towards and eventual into the series of holes). This is all acceptable to the players if they have a lusory attitude (i.e. they agree that these rule make this particular game possible).

Figure 1 presents our interpretation of Suit's treatise as it might relate to games making. While traditional games have pre-determined goals and rules, in games making students have the opportunity to explore and manipulate the means through which they develop lusory goals and constitutive rules. Further, this exploration involves a continuous to and fro process where changes in rules impact changes in goals and vice versa. In Figure 1, this process is represented by the double arrows between the constitutive rules and the lusory 
goal, as well as the loop between constitutive rules and filter in which students experiment with appropriate lusory means. As a consequence, to revisit the aim of this paper, we sought to determine if this figure (and the theory it represents) provides an appropriate heuristic for understanding student-designed games within physical education.

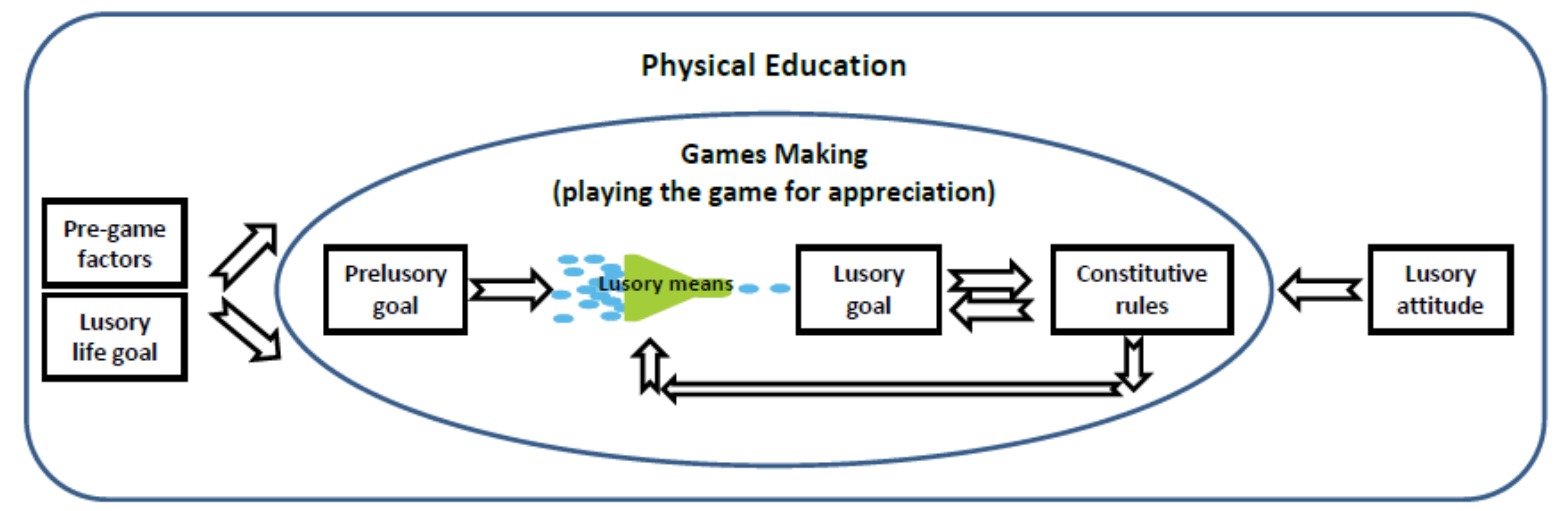

Figure 1. Application of Suits' game theory to games making

\section{Methods}

\section{Participants and setting}

The participants in this study were 58 year 10 students (14-15 years old) and two teachers from a mixed secondary school in the greater London area. The students were members of two physical education classes that each met three times a week for 45 minutes. These classes differed in that the students had been previously streamed into two different cohorts based upon their standard scores in Physical Education from previous years. What was common amongst the students however was that they represented all of the students within year 10 who had elected not to enrol in the formally GCSE (General Certificate in Secondary Education) examination in physical education or the BTEC Sport qualification on offer to them. As such, these students were engaged in "Core PE" and were described by their teachers as "a mix of generally disaffected children, able sports participants who had chosen not to be examined in the subject, and a group of academically gifted pupils who, similarly, had chosen not to gain a physical education qualification.” Indeed, it was the notion 
of "disengaged" that seemed to be the theme that ran through the entire cohort. In the words of two students, physical education was described as "a time to mess about for the whole time I've been at school" or "it's just like...sport and you just play...you come and get changed, go out on the courts or in here somewhere, then do some activities about a certain sport and then perhaps play the sport at the end of the lesson.”

The two teachers were both recently employed at the school. Steve, the department head, was just completing his first year, while Natalie had also moved to the school straight from University. Both teachers had become dissatisfied with the curriculum they inherited within the school, which could be described essentially as a multi-activity, "physical education as sport-techniques” (Kirk, 2010) method of presentation. As such, one of their goals was to provide their students with a form of engagement that was potentially more meaningful and motivating. As Natalie suggested:

I think for this particular group of kids we're working with, they're not particularly sporty, they're not particularly competitive, they're not particularly good at PE, it's one of those types of groups so for them to spend the next two years doing practical PE where we're saying "You need to get better at netball, you need to get better at hockey”, I think they're intelligent enough to know "why would I want to do that? I don't particularly enjoy it, I don’t have that particular edge."

As such, both teachers were committed to not "regurgitating the Key Stage 3

curriculum at Key Stage 4 and were willing to explore student designed games as a potential way of engaging more students.

\section{The games making unit}

The games making units comprised 21 lessons that were conducted during the students' weekly allotted physical education lessons, with all lessons taking place on the school's netball courts. Given the disparity between the enrolments in the two classes, the students were divided into teams of five or nine (depending on their class) by the teachers who attempted to make them as even as possible based upon their games-playing ability. 
The task for each team was to design a game using a web-based wiki as the platform for recording the game and sharing it with the other participants. The students had access to any equipment available within the school's physical education equipment room. All teams were given some basic guidance relating to both game design and issues such as health and safety to ensure that game development proceeded safely and equitably.

The unit was divided into three phases. First, the teachers allocated 6 lessons for students to explore previously untaught games such as Korfball, Tchoukball and Handball. This was followed by 9 lessons in which the students trialled and modified their games. During this time each team presented its game to allow for peer feedback. Finally, the final 6 lessons saw the teams making the final adjustment to their games and consolidating all the constitutive rules. Following this the students spent 20 lessons playing their games in a competitive league structure, which allowed all students to play and officiate (involving refereeing, time keeping, scoring and updating league results and tables on the wiki) in all of the created games (these lessons were not included in this study).

\section{Data collection}

Interviews were conducted with both teachers before the commencement of the unit, at mid-point, and on completion of the project. The first of these focused on the teachers' rationale for conducting the games making unit, and to explore their perceptions of the students' engagement in physical education. The second and third interviews focused more on students' responses as well as the teachers' understanding of games making pedagogies. Specifically, the key questions posed during these two interviews included the following: (1) How do you perceive the students' responses to the unit?; (2) What differences do you see in terns if participation in this unit and their previous games participation?; (3) What do you think the students have learned?; and (4) How have you found the change in terms of your own teaching practice? 
Interviews were also conducted with nine student teams immediately following the completion of their game-design segment. The goal of these interviews was to discover the students' rationale behind the particular games they had invented as well as their overall responses to the process of games-making. These interviews were conducted in a small meeting room, followed a semi-structured format, and lasted approximately 20 minutes. Five stimulus questions served to drive these interviews, which were recorded on a small digital recording device for later transcription. Those questions were: (1) How did this experience of games making compare with previous games lessons in Physical Education?; (2) Tell me about your game - how you went about designing it - how your group worked together; (3) Were there any features of the games making process that you found particularly enjoyable or just enjoyable?; (4) What were the biggest challenges or frustrations you encountered?; (5) What do you believe you have learned during this unit? The students were asked to elaborate on their responses in cases where their answers were limited, and were also encouraged to make comments beyond the specific questions.

\section{Data analysis}

All interviews were transcribed verbatim. The analysis occurred in three phases. First, the researchers systematically analysed the data using inductive analysis and constant comparison (Denzin \& Lincoln, 2003; Lincoln \& Guba, 1985). During several readings, each interview or log text was segmented into a series of thoughts and perceptions. Second, based on the work of Bell, Barrett, and Allison (1985), a thought or perception was defined as a statement that was conceptually consistent with a single topic or idea. Finally, thoughts and perceptions were compared to the hypothesized figure of student-designed games in order to answer the research question of the paper.

\section{Results}


In presenting the results, we have taken Figure 1 which we presented earlier in the paper and working from outside in and then from left to right, explore each aspect of the model in turn. Therefore the findings will be presented in subsections that relate to (1) pregame factors and lusory life goal (with respect to physical education), (2) lusory attitude, (3) lusory means, (4) lusory goals, (5) constitutive rules, and (6) the "decision" loop between constitutive rules and lusory means. Where we have used student voices in our presentation of the findings we have noted the gender (e.g. F) and the group (e.g. 3) of the student.

\section{Pre-game factors and the Lusory life goal (students' attitudes towards and goals}

\section{for physical education)}

The pre-game factors that related to games making in physical education revolved around the students' past experiences of games in a school curricular and extra-curricular context, as well as their attitude towards school in general and to physical education specifically.

In the main, physical education and games were socially constructed for these students as a subject for which they did not wish to gain an academic qualification. From discussions with the staff, students' involvement in either lessons and/or the school's extra-curricular programme could best be described as disengaged. According to Steve, the main explanation for this was that "there are a huge variety of kids in the group...some who love sport, some who hate sport, some who are academic, some who are not academic, some who like playing competitive sport, some that just like individual sports”. From the students’ perspective, taking part in physical education then was seen as something "I have to because it’s on my timetable” (M-1). Such indifference was supported by statements from students who suggested that "we just played a game, we got taught how to play the game and we played it" (F-1).

\section{Lusory attitude (the students' attitudes towards games making)}


In considering the challenges of games making we concluded that there were two parts to this aspect of game theory. Firstly, because games revolved around problem setting, there was a need for every group of students to come up with a problem. Secondly, the difficultly inherent in solving the problem is also dependent on the participants' willingness to abide within the common agreement to play by the rules.

Indeed, in analysing the data it became clear that the students either resisted or accepted these challenges. One class initially resisted the notion in game theory of "problem setting” to a point where they created problems that already had multiple existing and wellknown solutions. That is, their games essentially spliced two games together, for example the games of football and netball. They then opted to abide by existing (albeit hybrid) rules. For example, in creating the game "Netfoot", one team produced a game in which netball was played inside the goal circle and football was played on the rest of the court. The only rules of significance were the transitions between the two games, which required a player to flick the ball up into the netballer's hand or to roll the ball out to the footballer's feet.

In contrast, other students showed a real willingness to adopt the games-making challenge itself and to indeed create a novel game. As one student pointed out:

It's really hard not to copy other games because the game that we had was a mix between some games, it was a really good game but it was too much like the other games so we had to completely think out of the box 'cause we were thinking of some games and then we were like 'oh no, that's too much like football' or 'that's too much like netball or something' so we did have to think about that. (F-2)

The decision to deliberately seek out and solve a new problem, rather than simply regurgitating a familiar problem and an equally familiar solution, was fundamental in improving the lusory attitude of some students who had been described by their teachers as "negative” and "not in the slightest bit motivated".

The second aspect of lusory attitude is a willingness to abide within a common agreement to play by the rules. Given the decision by some students to develop combination 
games, it should have been relatively easy for them to abide by the rules, as they had already inherited their own history of rule adherence in regards to these two games. However, alongside their decision not to set particularly a new or difficult problem for themselves was an underlying attitude of disinterest towards the unit. When asked in their summer interviews, how seriously they took the games-making process one female student replied: "quite seriously but we didn't take it like really, really seriously, we were trying to enjoy it and be light hearted about the whole thing, it was good fun though.” (F-1)

For those students who searched for innovative problems, the agreement to abide by the rules of their games brought additional challenges. That is, in having (at least initially) less clearly defined rules allowed for the seeking out of loopholes in their own rules as well as those created by other groups. In his interview one student admitted that "trying out our game and finding out all the weak points was pretty fun” (M-8) while another classmate felt “it’s more interesting because you're making up your own game instead of following rules that have already been set by someone else, so you can adapt" (F-8).

Taken as a whole there was certainly a shift in students' lusory attitude towards their physical education lessons as they participated in the games-making unit. The following exchange represents a positive change in attitude that affected a number of the students:

M-5: We're not messing about as in just sitting down and chatting to each other, we're messing about doing the game.

M-5: We have fun doing the game and improving it, you enjoy doing and learning what you're doing.

F-5: You're playing but you're learning as well.

M-5: We're not taking it dead serious but still doing the game in a fun way.

F-5: Plus it's very enjoyable.

The feeling that the students had shifted from being a group who "quite often get disengaged" to one that were interested and challenged by physical education was a strong theme of the teachers' response to the unit. In particular, when asked to elaborate on what they meant by "motivated" Natalie mentioned that absence of comments such as "I really 
don’t like netball”, “I don’t want to do rugby” or “I really don’t want to go outside and do practical today", and that the shift was more to one of "wanting to do it and wanting to get out there and if they don't have their kit or they are injured, they seem to be, the majority seem to be still getting involved."

Steve, who worked with both classes, saw more of the difference between the two rather than just seeing the difference between the old and the new that Natalie saw. In particular he noted differences in the students' engagement in the different classes:

[one class] seem much more engaged, they're coming up as with good a games as the [the other class] but they seem more interested in the structure of the games and scoring, coming up with better systems in terms of how many points you get for different things and how you get people out and more imaginative ways of scoring.

However, the teachers’ opinions were not universally applied to all students. In

acknowledging the impact of the unit on some of the students, Steve felt that some missed the old approach to physical education:

I think some of them miss traditional physical education because they've done that for three years and that's their comfort zone and they're feeling a little bit confused, well not confused but unsure or just not very comfortable with this change, that is quite a big change for them so I think some of them just want to go back to the norm.

When asked to explain why this might be, he elaborated:

I think others have got real passion for certain sports and feel like they're missing out on that now because they're doing something different, so there's a couple of boys in there who are dead keen on football, couple of girls very interested in hockey and netball and I think they just want to get back to playing their sport because that's what they love.

\section{Lusory means (the permitted actions of the game)}

One of aspects of the games-making unit that created the biggest set of obstacles for the students was the openness of the games-making task. Because the games-making process was presented as a tabula rasa and the students were given a fairly free rein in terms of the games that they might develop, the scope was perhaps too broad. Physical education, which had 
previously been filled with activities and games that required students to do "something you were told to do" (F-6), had suddenly become about open choice and this was a big change. As noted earlier, for some this meant doing versions of what they had always done, while for others it was about being creative and coming up with an idea for a new game. Nevertheless, this was one of the hardest aspects of the whole process.

A specific challenge was bringing everyone ideas together to make a game that actually worked. Two comments are particularly pertinent here:

M-6: To start with there were like no ideas, then everyone had ideas but they were different, we had to try and merge them together to make something that worked, which was a real challenge, to get it to work.

F-5: You've got to make sure you get everything right because if you mess up in the game, no-one's really going to understand you. You have to make sure you can explain the game before you play it.

One of the core problems, for some students at least, was that they did not like having to go through the filter of the lusory means. Put simply, students did not like having to think of ways of limiting their ideas concerning the goal of their game by also limiting the permitted rules through which they could play. Indeed, as one female student suggested, “there’s a game for basically everything so to be completely different, the game will probably be really rubbish because there wouldn’t be any structure to it” (F-9).

The teachers were aware of the "discussions" and "negotiations” that the students were engaged in around the prelusory goals and lusory means of their games. When asked if the students were having these discussions amongst themselves,” Steve replied:

They are, yeah, they're having discussions, they're having arguments, they're going through that phase where they're all fighting for a little bit of power or trying to get their point of view across and I think that's great, You've just got to let them sort of see it through haven't you?

However, in the act of facilitating these discussions, Steve felt that his role was also changing: 
They do take some guiding, I think to keep it rolling You've got to get involved with some groups more than you do with others and give them a bit more guidance and a bit more...

\section{Lusory goals (defining how to win)}

Once of the students had "filtered" the prelusory goal for their games through the lusory means, they were then required to define how to win their games. For winning to occur the team must achieve the prelusory goal by remaining fully compliant with the lusory goal. The actualisation (and in some cases the realisation) of the lusory goal was a key turning point for many of the groups. A number of the students were happy with the idea of developing a game that tested their ability to "come up with a game” (i.e. setting themselves a testing goal). Where the real challenge came was in turning that test into a contest. Many of the students focused much more on the test (scoring points by overcoming a set of rules and obstacles), rather than the contest (outscoring their opponents to win the game). They were concerned with creating an "enjoyable test” (F-4) or a "valid challenge” (M-6) but struggled with the need to balance the need for uncertainty in the outcome with the level of skill of participants. In other words they could come up with a test that they could master as a group but when it came to defining a contestable game between two teams of unknown ability they found it more difficult.

When, in the interviews, the students were asked to consider why some of their initial ideas or games were (in their words) "boring” they felt that aimlessness and inactivity were key causes of boredom. When they were asked to define a good game the students had some clearer ideas as to what a good game should be:

F-2: Something that everybody enjoys including boys and girls.

F-2: Something that everyday can play, for example a football game, girls might not really like it whereas netball, boys might not really like it so a game that everybody can do and that everyone will enjoy. M-2: It's not individual to one personality or gender, anyone and everyone can enjoy it really. 
F-3: Not too complicated.

M-3: It has to be fun.

F-3: Active.

F-3: Quite clever.

Clever seemed to be important for some students. In a similar vein to games-makers in previous studies (see Casey \& Hastie, 2011; Casey et al, 2011) the search for innovation was seen as being important. Tried and tested was seen as the norm and therefore consistent with regular physical education, new was better. When asked to explain "clever" the same student continued:

F-3: Not like the usual pass it round score game but something different. Interviewer: Was difference important?

F-3: Yeah. [some other students agree] It made it more fun because you hadn't done it before so just had to try out the new game.

"Newness” was not the only aspect of a good game that the students highlighted. For them the game needed to be enjoyable. Consequently the lusory goal needed to ensure that students also enjoyed what they were doing. There was certainly the tacit belief that for something to be enjoyable it had to be popular and fair - something that the games played in physical education were not.

\section{Constitutive rules (restrictions put in place)}

The biggest gulf experienced by the students seemed to be between the desire to have a lusory goal that made things fun, new, and enjoyable, with the reality of developing a set of constitutive rules that made that goal possible. Indeed, the students engaged in a lot of vacillation between their aim for fun and enjoyment and the development of a rule set that allowed for this.

In their interviews the students spoke primarily about the challenges of making their games work, especially when they were subjected to the scrutiny of others through game play. The development of constitutive rules was likened by some players to fixing bugs in the game in the same way that a programmer would fix a poorly behaving computer game. 
Sometimes this occurred through observations of their game being played by others and sometimes from the feedback they were given from other students in the guise as players of their game. Some of this “fixing” also occurred as a result of playing other team's games and identifying aspects of these games that they either liked or thought would improve their objective of enjoyable fun.

At their heart, these constitutive rules were functioning to achieve the enjoyable test within the lusory goal. Nevertheless, they did not always serve to facilitate a good contest. This was evident in both hybrid games where the established rules of netball and football impeded the need for something that was new - and in the truly "new" games, where the evolution from test to contest had not yet occurred. This meant that the loop identified in Figure 1 from constitutive rules to lusory goals (often via the filter of lusory means) was a much-travelled route for some of these teams.

\section{The loop from constitutive rules with lusory means (making game adjustements)}

The toing and froing between rules, goals and means was neither liner nor regular.

Importantly though, this period of shift and transition was seen by the students and the teachers as supporting both enjoyment and autonomy. Two groups provided particularly poignant comments:

M-4: It was something different, we felt like we were more involved and it was much more interesting and it was more fun.

F-4: It's like different because when we do a normal physical education lesson, we stand around for 15 minutes with them going, "okay we're going to do this". F-4: It's more fun than normal physical education and you've got a responsibility to look after people who are playing your game, tell them the rules, so that's a bit better than normal physical education.

F-4: I like it because you get to make your own rules of your own game, you don't have to follow by the rules of other games and you can use your own ideas.

M-5: It's good that it's not just you're told a game and you go do it, you actually think more about it and so the more academic people like it more than just running about to buy a bunch of rules. 
At its heart, however, this loop provided the students with a very real (to them and their teachers at least) sense of both understanding about games and their rule and game appreciation. As two students commented:

F-4: I think it was really different because before we just played a game, we got taught how to play the game and we played it whereas this time you'd got to think more about why other games are like, why other games are good so you've got to try and make your game good.

M-4: And it's good because you need to find out why they work and apply those skills to your game.

When asked to describe what he felt the students learnt as a consequence of the games making experience, particularly the interplay between rules, goals and means, Steve replied:

I think some are surprised at how much they needed to think about creating a game and I think for some, it was quite interesting to see the first time they tried to play it themselves as a group, suddenly there was loads of arguments, "that's not the rules”, "this isn't the rule and why are we doing this?” and I think they then thought "crikey, we need to think of a hell of a lot more rules than we've got”.

\section{Discussion}

The purpose of this paper was to provide answers to the following three key questions. These were: (1) How does a unit of student-designed games add to the meaning that previously disengaged students see in physical education? (2) To what extent can Suits' theory of games be modified to explain these student responses? (3) To what extent can Suits' theory help provide a deeper explanation of the previous findings of student-designed games that students appreciate engagement?

Based on the findings reported above, we are confident in our suggestion that Suits’ (1978) theory of games (and our representation of his ideas as a model - see Figure 1) provides an appropriate heuristic for understanding student-designed games within physical education. Fundamentally, what emerged from the data was the sense, for many of these children, that their physical education lessons were now more meaningful. They no longer defined physical education as "just like...sport and you just play...” and nor was it a time when they just “mess[ed] about.” Even for those children who were challenged by the games- 
making process still talked about PE differently. The games, their games, took a different role in their lessons. They now needed to be 'fun, new, and enjoyable' and when they were not they needed to be 'fixed'. Capital, we would argue, was now being won for having a good game rather than for being a good player.

By his own admission Suits (1978, p. 22) badly theorized work as a "technical activity" through which, he intimated, work was an "activity in which an agent seeks to employ the most efficient available means for reaching a desired goal.” While this might be considered a crude analogy for the complexities of work it does allow us to make a direct comparison between work and games. Work, Suits argued, was in stark contrast to the "means employed in games [which] are not the most efficient" (p. 22). In some ways it was the contrast between "work-focused" school efficiency and "games-focused" play inefficiency that caused many of the participants in this study the most problems. It was not so much that the students could not think of new ideas - although this was a problem for some - it was that this thinking was too much effort and it did not allow them to get on with the business of playing. It could be argued that physical education has been guilty of the same efficiency drive of work that these students advocated. In reducing the complexities of games to skills and techniques, the complexity and inefficiency of games better fits the constraints of the industrial age school (Lawson, 2009) with its timetables and processes. Yet in doing so it moves beyond the premise that we work so that we can play (Morgan, 2006). Indeed Suits (1978, p. 9) himself suggested "our labour is valuable because it permits us to play.” It does not seem unreasonable to suggest that games generally - and games makingspecifically - might be the very antithesis of the efficiency that Suits was talking about. Even the most established and refined of games is unpredictable: if they were not so capricious then 'match-fixing' would not be the curse that it is. However, in this drive for efficiency some of the other core elements of games, play, and game play are missing. When a game is 
reduced to its core skills, or when actions are taught in relation to the rules but the rules themselves are not explored or tested, then learners re-enact movements rather than being responsive to situations. Yet games are means-end-orientated activities and rule-governed activities (Suits, 1978) in which winning is a finite event that is achieved (or not) only through adherence to pre-prescribed rules. Therefore, games learners and developers need an understanding of the actions and interactions of rules and means if they are to enhance their understanding of games. Such is the "inseparability of rules and ends in games” (Suits, 1978, p. 24) that it seems remiss of physical educators and coaches to somewhat ignore the relationship between these two important facets of games.

One element of games that has been a focus of physical education - particularly physical education as sport-techniques - has been the "rule of skill” (Suits, 1978, p. 37). Suits held that "to break a rule of skill is usually to fail, at least to that extent, to play the game well, but to break constitutive rule is to fail (at least in that respect) to play the game at all” (p. 38). We would argue that the key focus of the games that these students were used to playing was the need to "play the game well”. Indeed it could be argued that the main focus of physical education has been playing well and the opportunity to just play is removed from students as the opportunity arises. To this end we suggest physical education has been using an impoverished version of Suits' (1978) theory which is illustrated in Figure 2.

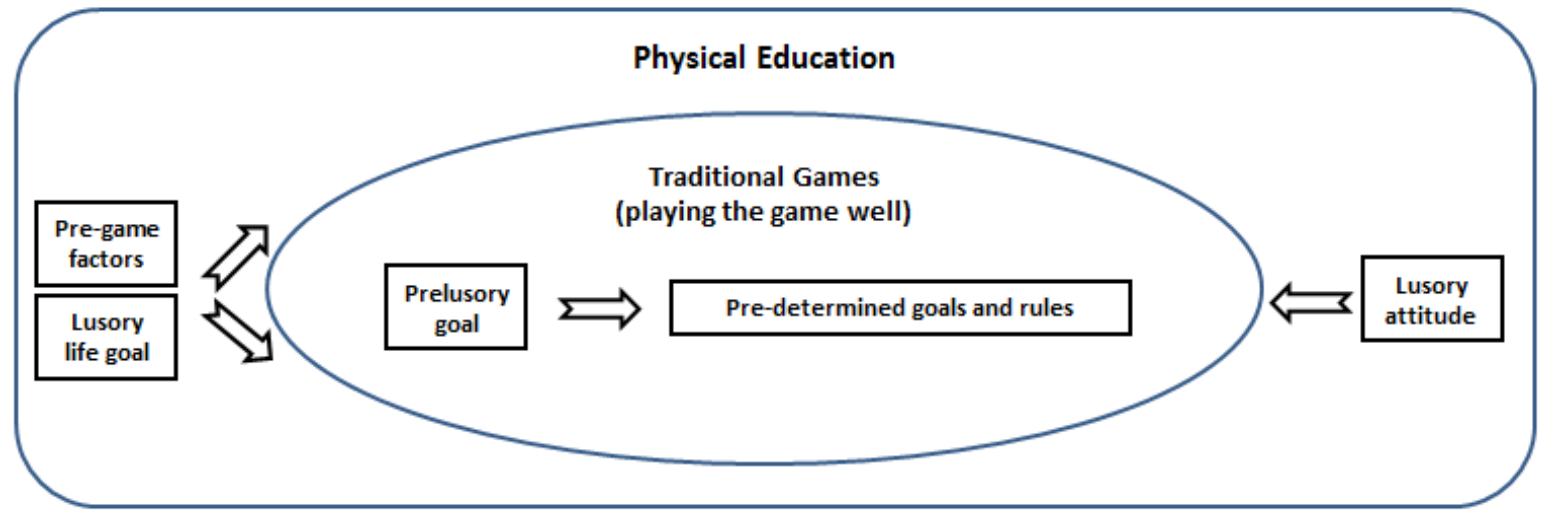

Figure 2. Application of Suits' game theory to traditional games teaching 
In this figure, the loop (and its associated toing and froing) between lusory means, lusory rules, and constitutive rules is replaced with predetermined rules and goals and the aim of playing the game is superseded by the need to play the game well. Such an approach, with its focus on specific outcomes through the mastery of specific "sport-techniques”, limits (as much as the unpredictable of games can be limited) the scope of acceptable outcomes available to teachers and student alike. In other words, this approach adopts "work-focused" school efficiency as opposed to "games-focused” play inefficiency and its subsequent potential for learning and game appreciation. Put differently, the instrumental outcomes of traditional physical education were replaced with activities that had worth in and of themselves (Tinning, 2009).

The drive for efficiency in teaching is not unique to physical education and nor is this problem new but the application of Suits' model allows us to view it through a different lens. Siedentop (1994) has not been the lone voice in arguing that many children and young people lack the tactical and strategic acumen to be successful games players (see Mitchell, Oslin, \& Griffin, 2013). Indeed the ubiquitous focus on the acquisition of sport-techniques has been seen as the catalyst for the development pedagogical models such as Sport Education and Teaching Games for Understanding and yet, despite the birth of these pedagogical models, the teaching of strategy remains difficult. Perhaps, as is shown in this study, only by moving away from established games and their prerequisite skills, and having students make their own games, does the significance and importance of tactics, strategies and rules become overt. Only by moving away from the comfort of traditional national games such as cricket and netball and heading into the unknown can we start to help students to build up their understanding rather than disseminating information we deem pertinent to given sporttechniques. 


\section{Conclusion}

Physical education has increasingly been seen as an important mechanism in the delivery of instrumental outcomes such as ‘sports talent ID’, 'decreasing obesity’, and ‘citizenship’ (Tinning, 2009). However, in aspiring to such ethereal outcomes the subject continues to act in old and established ways. Value and worth is placed, not on the activities having worth in and of themselves but rather on other extrinsic or instrumental measures (Tinning 2009). Playing the game well is valued above all others things and students are assessed in molecularaized forms of activity (Jones et al., 2014) and against measures of performativity (Evans, 2013).

In contrast, the findings from this study provide support for our notion that we might be more able to provide meaningful experiences to students in physical education if we were to follow a more philosophically-driven and less efficiency-driven approach to games, and perhaps follow Suits' (1978) lead a little more closely. That is, while the well-played game is pleasing to our eyes (as players ourselves and as literate sports fans) perhaps the well-played game is not the core function of physical education. If, as Kretchmar (2005, p. 153) suggests, we need to make playgrounds to "help our students...find the better and more captivating varieties of play [then, in short,] we need to become highly skilful playmakers.”

We suggest that physical education needs to "get over" its reluctance to break the rules of skill and focus on what the rules actually allow us to achieve in our game play. As this study has shown, by exploring the loop between and around lusory means, lusory goals and constitutive rules (the aspects of Suits' (1978) theory that have been shown to represent student-designed games) students engage with a more meaningful games experience than when they established games in regulative ways. Furthermore, and in developing findings from previously published work on student-designed games (see Casey and Hastie, 2011; Casey et al. 2011), the search for meaning is not inherent in all students, as some just want to 
play. Students have lost the inquisitiveness that, it could be argued, is the hallmark of both children and outstanding players - players who are frequently lauded for ripping up the rulebook and doing the unexpected. Finally, while current physical education, with its preponderance for "sport-techniques” serves to satisfy those young people who want to play the game well it also alienates those previously marginalized (Ennis, 2000) by pre-game factors and their lusory life goals. In contrast, student-designed games afford students with the chance to overcome and change those factors that come from outside of physical education and yet which have such an impact on participation. 


\section{References}

Arnold, P. (1985). Rational planning by objectives of the movement curriculum. Physical Education Review, 8(1), 50-61.

Bell, R., Barrett, K. R. \& Allison, P. C. 1985. What preservice physical education teachers see in an unguided, early field experience. Journal of Teaching in Physical Education, 4, 81-90.

Casey, A., \& Hastie, P. A. (2011). Students and teacher responses to a unit of studentdesigned games. Physical Education \& Sport Pedagogy, 16, 295-312.

Casey, A., Hastie, P. A., \& Rovegno, I. (2011). Student learning during a unit of studentdesigned games. Physical Education and Sport Pedagogy, 16, 331-350.

Denzin, N.K., \& Lincoln, Y.S. (2003). The landscape of qualitative research: Theories and issues ( $2^{\text {nd }}$ edition). Thousand Oaks, Ca: Sage Publications Inc.

Ennis, C.D. (2000). Canaries in the coal mine: responding to disengaged students using theme-based curricula. Quest, 52, 119-130.

Evans, J. (2013). Physical Education as porn! Physical Education and Sport Pedagogy, 18, 1, 75-89.

Hastie, P. A. (2010). Student designed games: Strategies for promoting creativity, cooperation, and skill development. Champaign, IL: Human Kinetics.

Hastie, P. A., \& Andre, M.H. (2012). Game appreciation through student designed games and game equipment. International Journal of Play, 1(2), 165-183.

Jones, R., Harvey, S., \& Kirk, K. (2014). Everything is at stake; yet nothing is at stake: exploring meaning-making in game-centred approaches, Sport, Education and Society, DOI: 10.1080/13573322.2014.965138

Kirk, D. (2009). A physical education for the future or a future for physical education? In L.D. Housner, M.W. Metzler, P.G. Schempp, \& T.J. Templin, (eds.), Historic 
Traditions and Future Directions on Teaching and Teacher Education in Physical Education (pp. 137-148). Morgantown, WV: Fitness Information Technology.

Kirk, D. (2010). Physical education futures. London: Routledge.

Kretchmar, R. S. (1994). Practical philosophy of sport. Champaign, IL: Human Kinetics.

Kretchmar, R. S. (2001). Duty, habit, and meaning: Different faces of adherence. Quest, 53, 318-325.

Kretchmar, R. S. (2005). Practical philosophy of sport and physical activity (2nd ed.). Champaign, IL: Human Kinetics.

Kretchmar, R. S. (2007). The normative heights and depths of play. Journal of the Philosophy of Sport, 34, 1-12.

Lawson, H. A. (2009). Paradigms, exemplars and social change. Sport, Education and Society, 14, 97-119.

Lincoln, Y.S. and E. Guba. 1985. Naturalistic inquiry. Newbury Park, CA: Sage.

Mitchell, S. A., Oslin, J. L., \& Griffin, L. L. (2013). Teaching sport concepts and skills: A tactical games approach for ages 7 to 18. Champaign, IL: Human Kinetics.

Morgan, W. J. (2006). Philosophy and physical education. In D. Kirk, D. Macdonald, \& M. O’Sullivan (eds.), Handbook of physical education (pp. 97-108). London: Routledge.

Peters, R. (1996). Ethics and education. London: Allen \& Urwin.

Rovegno, I. (2008). Learning and instruction in social, cultural environments: Promising research agendas. Quest, 60, 84-104.

Siedentop, D. (1982). Movement and sport education: Current reflections and future images. In M. Howell, \& J. E. Saunders (eds.), VII Commonwealth and International Conference on Sport, Physical Education, Recreation and Dance (pp. 3-13). Brisbane: University of Queensland Press 
Siedentop, D. (1994). Sport education: Quality PE through positive sport experiences. Champaign, IL: Human Kinetics.

Siedentop, D. (2009). Research on teaching physical education: Celebrating our past and focusing on our future. In L.D. Housner, M.W. Metzler, P.G. Schempp, \& T.J. Templin, (eds.), Historic Traditions and Future Directions on Teaching and Teacher Education in Physical Education (pp. 3-14). Morgantown, WV: Fitness Information Technology.

Suits, B. (1978). The Grasshopper: Games, life and utopia. Toronto: University of Toronto Press.

Tinning, R. (2009). Who pushed Humpty Dumpty? Dilemmas in Physical Education circa 2007? In L.D. Housner, M.W. Metzler, P.G. Schempp, \& T.J. Templin, (eds.), Historic Traditions and Future Directions on Teaching and Teacher Education in Physical Education (pp. 149-154). Morgantown, WV: Fitness Information Technology. 